\title{
Diagnostic Accuracy of Doppler Ultrasound Technique of the Penile Arteries in Correlation to Selective Arteriography
}

\author{
Helmut Gall,' Wolfgang Bähren, ${ }^{2}$ Wolfgang Scherb, ${ }^{3}$ Christian Stief. ${ }^{4}$ and Walter Thon ${ }^{4}$ \\ Deparments of 'Dermatology, 2 Radiology. "Neurology. and ' Lrology, Federal Army Hospital, Llm, FRG
}

\begin{abstract}
In $63 \%$ of 265 patients with erectile dysfunction a relevant arterial inflow disturbance was found by Doppler ultrasound examination. Correlation between Doppler and arteriography in 58 patients showed an accuracy of $95 \%$ in detecting penile arteries and an accuracy of $91 \%$ in discovering a pathological arterial pattern (arterial anomaly or arteriosclerotic obstruction). In 15 patients the arterial inflow was measured additionally by Doppler ultrasound technique after intracavernosal injection of vasoactive drugs (IIVD) $(7.5 \mathrm{mg}$ papaverine and $0.25 \mathrm{mg}$ phentolamine). This technique proved to be more reliable than in the flaccid state and markedly facilitated localization and assessment of pathological changes of the cavernosal arteries.
\end{abstract}

Key words: Erectile dysfunction-Doppler ultrasound-Arteriography -Corpus cavernosum injection-Vasoactive drugs-Penile arteries

The Doppler ultrasound offers a noninvasive method for evaluating an arterial origin of erectile dysfunction. The blood supply of the corpora cavernosa derives from the cavernosal branch of each penile artery, as well as small additional branches from the dorsal penile artery [1]. In 1975, Abelson [2] determined for the first time the systolic penile blood pressure by means of Doppler ultrasound; it is usually evaluated in relation to the systemic (brachial) blood pressure and is designated as the penile-brachial index (PBI). Later, Doppler examinations of the penile arteries in the flaccid state were performed by recording the velocity curve. For this purpose, directional Doppler flowmeters

Address reprint requests to: Dr. H. Gall, Bundeswehrkrankenhaus UIm, Dermatologische Abteilung, Oberer Eselsberg 40, D$7900 \mathrm{Ulm}$. West Germany with an ultrasound probe of 8 and $9 \mathrm{MHz}$ were used. Doppler examination of the four penile arteries in the proximal and distal segment was introduced by Jevtich [3] and by Karaćan et al. [4]. A further advance was the use of Doppler ultrasound of the penile arteries in association with the intracavernosal injection of vasoactive drugs (IIVD) [57l. A new technique for quantification of penile blood flow. duplex sonography and pulsed Doppler spectrum analysis, was introduced by Lue et al. [8]. They measured the diameter and the peak flow velocity of the dorsal and cavernosal arteries before and after intracavernosal injection of vasoactive drugs (IIVD).

Arteriography of the internal pudendal artery, on the other hand, represents an invasive testing method. The pioneering technique was described by Ginestié [9] and Juhan et al. [10]. Today selective arteriography of the internal pudendal artery is performed via pharmaco-angiography, generally under peridural anesthesia [11,12].

It was the goal of the present study to evaluate the extent to which the noninvasive penile Doppler ultrasound technique is able to detect disturbances of arterial penile circulation as the cause of primary or secondary erectile dysfunction. Bilateral selective arteriography of the internal pudendal artery and its penile branches after intracavernosal application of vasoactive drugs was considered the final determinant of diagnosis.

\section{Materials and Methods}

From Octcher 1981 to August 1986. 265 patients with erectile dysfunction (a: 2 rage age 45.5 years) were evaluated according to the multidiscirinary testing program shown in Table 1. In all patients. Dorrer ulirasound of the four penile arteries was performed with ite penis in the flaccid state. The penile vessels in the proximal $=x d$ distal segment were examined by a technique modified from !evich [3] using the directional Doppler flowme- 
Table 1. Multidisciplinary evaluation program

Medical and sexual history

Physchological interview and psychometrics

Laboratory (blood lipids, glucose tolerance test, liver en-

zymes, testosterone, prolactin)

Electrocardiography

Physical examination

Nocturnal penile tumescence (NPT) measurements

Bulbocavernousreflux (BCR)-latency

Doppler ultrasound

Table 2. Doppler results in 265 patients with erectile dysfunction

$\begin{array}{lr}\text { Normal sound on all }+ \text { penile arteries } & 41 \\ \text { Pathologic sound on } 1 \text { dorsal artery } & 52 \\ \text { Pathologic sound on } 2 \text { dorsal arteries } & 5 \\ & 98 \\ \text { Pathologic sound on } & 12 \\ 1 \text { deep artery } & 49 \\ 1 \text { deep artery }+1 \text { or } 2 \text { dorsal arteries } & 20 \\ 2 \text { deep arteries } & \frac{86}{167} \\ 2 \text { deep arteries }+1 \text { or } 2 \text { dorsal arteries } & \frac{167}{265}=63 \% \\ & \end{array}$

ter 762 by Kranzbühler. An $8 \mathrm{MHz}$ probe was applied. which is particularly suitable for superficial vessels. The penetration of the ultrasound cone ranges from 0.25 to $3.6 \mathrm{~cm}$ [13]. In 15 patients (average age 46.3 years), Doppler ultrasound was performed before and after IIVD.

\section{Doppler Ultrasound Technique of Penile Arteries in Flaccid State}

Localization of Vessets. The superficial dorsal artery is first localized proximally above the root of the penis. The ultrasound probe is placed in the midline dorsally at the root of the penis at an angle of $45^{\circ}$ to the horizontal plane. The ultrasound probe is shifted to both sides in order to evaluate the left and right dorsal penile artery. The distal positioning occurs in the sulcus coronarius. If no pulse sound can be demonstrated, the course of the dorsal penile artery is followed along the dorsum of the penis. The disappearance of the Doppler signal is recorded as the site of discontinuance.

The Doppler signal over the deep cavernosal artery is localized on both sides proximally at the lateral surface of the root of the penis. At first, the Dopper probe is placed laterally on the dorsum of the penis and is then moved into a dorsal-ventral curve. When the deep artery is reached by the ultrasound cone. the probe is tilted at $45^{\circ}$ to the vertical plane. The optimal distal recording site for the deep artery was found to be about $2 / 3$ of the distance from the penile root to the sulcus coronarius.

Assessment of the Doppler Signat. With respect to accurate recordings of the flow curves, it is important that the Doppler probe aims directly at the center of the vessel, otherwise one measures the velocity of the considerably slower marginal flows instead of the mean instant fow velocity over the vascular crosssection [13]. Furthermore, the pulses of ultrasonic waves have to be directed at an angle of exactly $45^{\circ}$ to the surface, if possible, which provides the clearest Doppler signal. The Doppler signal is

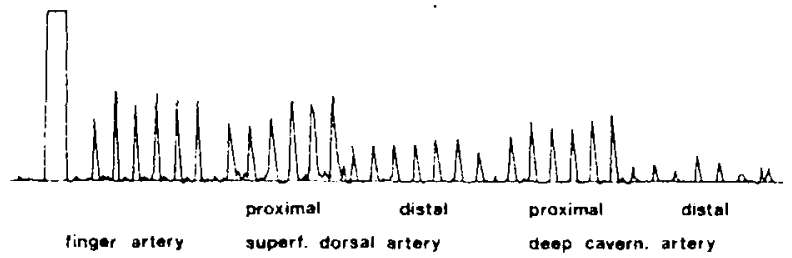

Fig. 1. Doppler sound of the penile arteries is analyzed in comparison with the artery of the index finger. A strong Doppler sound in the proximal segment of the superficial dorsal artery and deep cavernosal artery shows the same amplitude as the finger artery. Amplitude is decreased in the distal segment.

analyzed in comparison with the velocity curve over the arteria digitalis palmaris of the index finger. A strong Doppler signal over the proximal penile arteries shows about the same amplitude (Fig. 1). The amplitude normally decreases in the distal vascular segment.

In pathological cases there are weak Doppler signals, with the velocity curves showing an amplitude that is low or not at all measurable. In isolated cases, no Doppler signal can be recorded. When documenting the Doppler findings, the strong signal was marked + , the weak signal $(+)$, and the missing signal was marked 0 . Overall, there were eight localizations for the paired superficial dorsal artery and the deep cavernosal artery in the proximal and distal segment.

\section{Doppler Ultrasound Technique of Penile anteries by IIVD Testing}

In 15 patients, Doppler examination of the penile arteries was performed before and after IIVD testing. For this purpose, $0.5 \mathrm{ml}$ of the IIVD solution $(7.5 \mathrm{mg}$ papaverine and $0.25 \mathrm{mg}$ phentolamine) were injected into the right corpus cavernosum. Doppler ultrasound was performed $3-5$ min after the injection. during increasing tumescence. The four penile arteries in the proximal and distal segments were localized, and the velocity curves were recorded. For the purpose of quantification, the resulting amplitudes were compared to the velocity curves, which had been determined during artificial erection with IIVD solution in potent men.

\section{Arteriography}

In 58 of the 265 patients examined by Doppler ultrasound, additional selective bilateral angiography under peridural anesthesia was performed. The internal pudendal antery and the penile vessels were demonstrated following prior injection of the IIVD solution (15 mg papaverine and $0.5 \mathrm{mg}$ phentolamine) into the corpus cavernosum. The technique of selective pudendat arteriography in association with intracorporal injection of vasoactive drugs is described in detail in another article of this monograph.

\section{Results}

\section{Findings Obtained by Doppler Ultrasound}

The findings obtained by Doppler ultrasound in 265 patients with erectile dysfunction are shown in Table 2. A strong Doppler signal over all four penile arteries was found in 41 patients and a reduced 
Table 3. Doppler results before and after IIVD testing in 15 patients

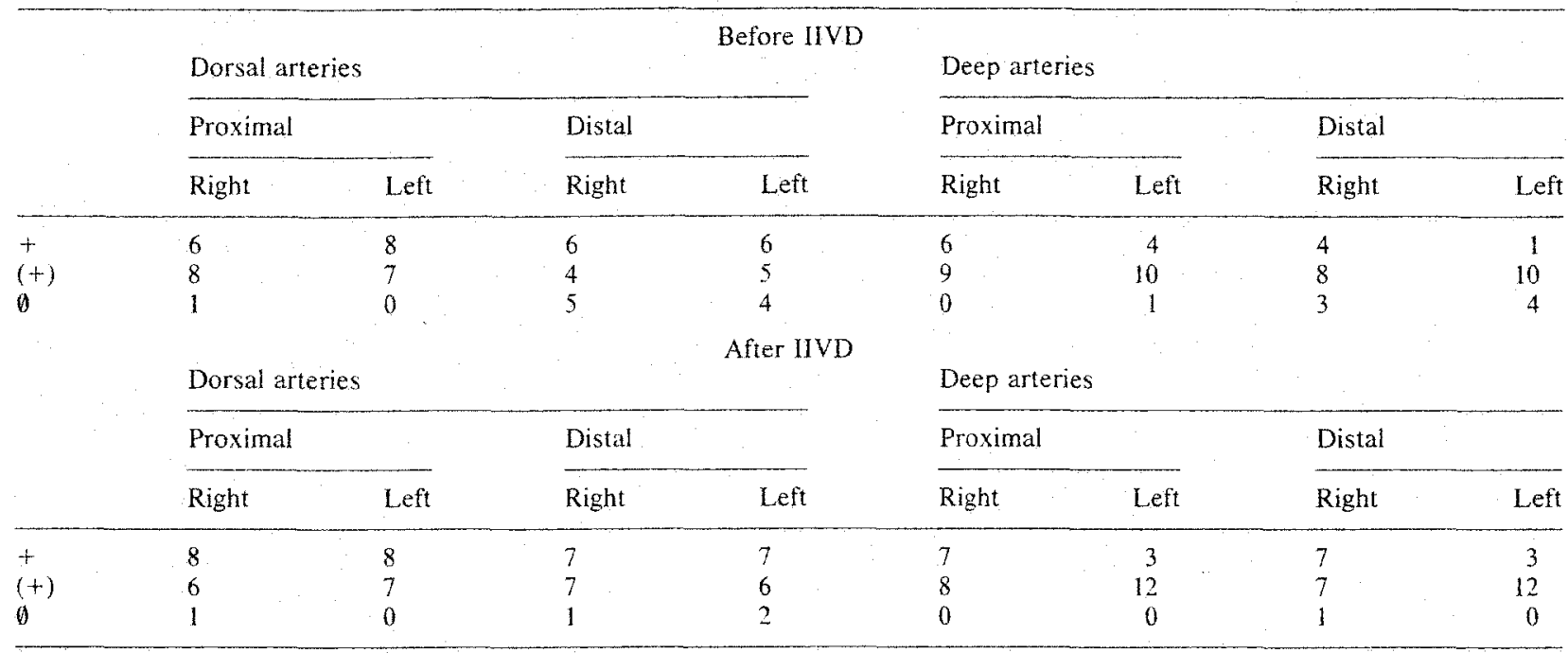

$+=$ strong signal

$(+)=$ weak signal

$0=$ no signal

Doppler signal over one dorsal artery was found in 52 patients and over two dorsal arteries in 5 patients. A pathological Doppler signal from one or two deep arteries, alone or in combination with dorsal arteries, was detected in 167 patients, and was the criterion of significant abnormality.

The results of Doppler ultrasound in the $15 \mathrm{pa}$ tients before and after IIVD testing are shown in Table 3. In comparative Doppler studies following IIVD testing, an additional vessel was localized in 13 of 120 measuring points. In most cases, there had been a reduced Doppler signal in the distal segment of a deep artery. Following IIVD, the flow curves over the deep artery and the dorsal artery usually showed higher amplitudes. The penile acceleration rate (the quotient of the amplitude of the velocity curves with and without IIVD) increased two- or threefold (Fig. 2). A comparative qualitative analysis of the Doppler signal was performed before and after IIVD (always measured against the individual control). After IIVD, an improvement was found at 16 measuring sites of the distal dorsal and cavernosal arteries and a deterioration at three measuring points of proximal cavernosal arteries (net increase of 13).

\section{Findings Obtained by Arteriography}

Bilateral selective arteriography of 58 patients revealed a pathological arterial pattern in 49 cases (Table 4). In 30 cases, angiography showed penile arterial anomalies; these were classified according to Bähren [11] (Table 5). Angiography showed pre-
Table 4. Results of arteriography in 58 patients with erectile dysfunction

\begin{tabular}{lr}
\hline Arterial anomaly & 30 \\
Arteriosclerosis & 13 \\
Art anomaly + arteriosclerosis & 3 \\
Posttraumatic changes & 3 \\
Normal & 9
\end{tabular}

Table 5. Arteriographic findings in 30 patients with arterial anomalies

\begin{tabular}{lr}
\hline Unilateral anomaly & 3 \\
Hypo- or aplasia of one penile artery & 2 \\
Hypo- or aplasia of two penile arteries & 6 \\
Bilateral anomalies & 19 \\
Bilateral hypo- or aplasia & \\
Complex malformation &
\end{tabular}

dominantly complex anomalies and bilateral hypoplasia or aplasia of the penile arteries. Isolated arteriosclerotic lesions were present in 13 patients, and in association with arterial anomalies in three additional patients. The low incidence of arteriosclerotic obstructions in this series is due to our criteria of exclusion (occlusive vascular disease as of stage III, severe coronary heart disease, and age over 65 years).

Arteriography in the patients with arteriosclerosis generally showed stenoses and occlusions in the terminal part of the internal pudendal artery bilaterally. Posttraumatic changes occurred in 3 patients in whom arterial obstructions were observed in the 


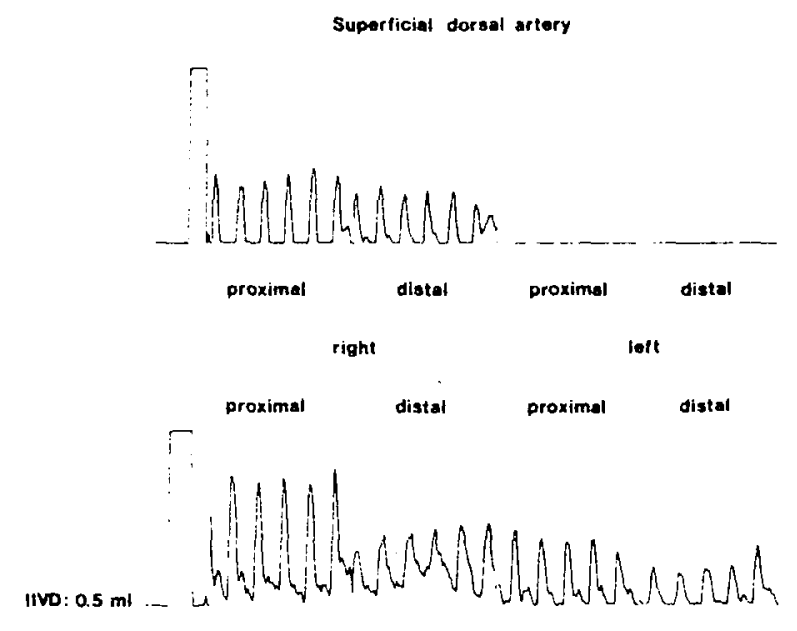

A

Deep cavernosal artery

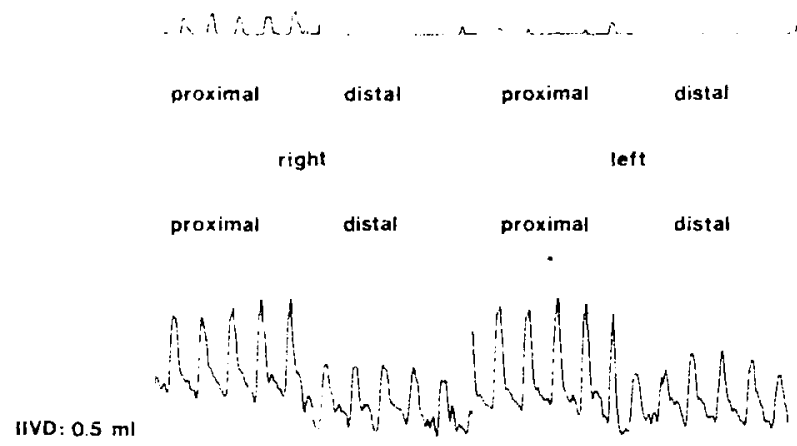

B

Fig. 2A. Accelerated flow in the superficial dorsal artery after IIVD. The amplitude of the velocity curve increases on the right and a velocity curve appears on the left. B. Accelerated flow in the deep cavernosal artery after IIVD. The amplitude of the velocity curves increases in the proximal segment, and a velocity curve appears from the distal segment.

penile artery at the level of the urogenital diaphragm. (see also Bähren et al., this issue). In 9 patients, arteriography showed a normal arterial pattern with four patent penile arteries. Six of these 9 patients had unilateral supply to the corpora cavernosa.

\section{Correlation of Doppler Ultrasound and Arteriography}

Doppler and arteriographic findings could be compared in 58 patients (Table 6). In 46 cases with hypoplasia or aplasia of the penile arteries, arteriosclerotic stenoses and occlusions, or posttraumatic obstructions, abnormalities were seen by both angiography and Doppler ultrasound (true-positives). In 2 cases, Doppler examination was abnormal
Table 6. Correlation of Doppler ultrasound and arteriography demonstrating pathological changes in 58 patients

\begin{tabular}{lrl}
\hline Doppler/Angiography & Angio pathologic & Angio normal \\
\hline Doppler pathologic & 46 & 2 \\
Doppler normal & 3 & 7 \\
\hline
\end{tabular}

Table 7. Assessment of pathological vascular findings

$\begin{array}{llll}\text { Sensitivity } & =\frac{\mathrm{tp} \times 100}{\mathrm{tp}+\mathrm{fn}}=\frac{46 \times 100}{46+3}= & 93.8 \% \\ \text { Specificity } & =\frac{\mathrm{tn} \times 100}{\mathrm{tn}+\mathrm{fp}}=\frac{7 \times 100}{7+2}= & 77.7 \% \\ \text { Accuracy } & =\frac{\mathrm{tp}+\mathrm{t} \mathrm{l}}{\mathrm{total}}=\frac{46+7}{58}= & 91.3 \%\end{array}$

$\mathrm{t} p=$ true-positive, $\mathrm{tn}=$ true-negative, $\mathrm{fp}=$ false-positive, $\mathrm{fn}=$ false-negative

whereas arteriography was normal (false-positives). In 3 cases, Doppler showed normal pulse sound despite arteriographic evidence of severe arteriosclerosis in the distal internal pudendal artery (falsenegatives). Seven normal arteriograms with two dorsal penile and two cavernosal arteries each were confirmed by Doppler ultrasound (true-negatives). Six of these cases were those with unilateral origin of the cavernosal arteries.

The sensitivity of Doppler ultrasound in detecting pathological changes in the penile arteries was found to be $93.8 \%$ (Table 7). Specificity was $77.7 \%$, and overall accuracy was $91.3 \%$.

The value of Doppler ultrasound in localizing penile vessels can also be assessed by comparing findings of Doppler and arteriography for proximal and distal segments of both arteries bilaterally (Fig. 3 ). The graph shows high accuracy in detecting normally patent superficial dorsal arteries and slightly reduced accuracy regarding the deep cavernosal arteries. This is due to the fact that the deep artery is more difficult to localize [14] and that, in addition, it shows fluctuations in the blood supply [15]. Localization by Doppler ultrasound was possible in 354 of 376 angiographically determined segments of the penile arteries $(94.1 \%)$. In 22 segments, Doppler failed, whereas angiography revealed arteries with a markedly reduced diameter. On the basis of 464 measuring segments used in 58 patients, the accuracy of Doppler (sum of positive and negative correspondence) was $95.2 \%$.

\section{Discussion}

In order to provide quantifiable information on the arterialization of the flaccid penis, the penile-brach- 
PROXIMAL

DISTAL

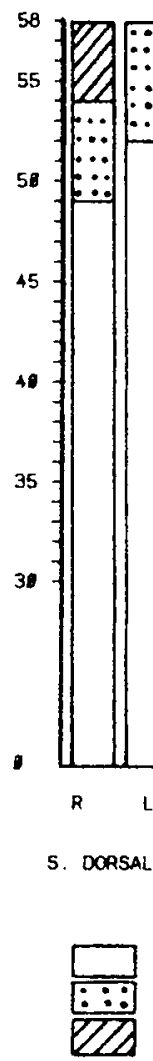

TRUE NEGATIVE

FALSE NEGATIVE

Fig. 3. Correlation of Doppler ultrasound and arteriography in localizing penile arteries. The graph shows good agreement in detecting superficial dorsal arteries and a slightly reduced accuracy for deep cavernosal arteries.

ial index (PBI) was determined for the first time in 1975 by Abelson [2] by means of Doppler ultrasound. A PBI $<0.6$ is regarded as a diagnostic criterion of erectile dysfunction of arterial origin [4,1618]. However, comparative studies of PBI and arteriography of the internal iliac artery showed that the $\mathrm{PBI}$ is not reliable in indicating the presence of a proximal stenosis in the area of the internal iliac or internal pudendal arteries $[11,12,19]$. Moreover, it is not very reliable in the identification of vascular anomalies [12]. Overall, we think that the PBI is only of limited importance with regard to the evaluation of a disturbed arterial blood supply in anomalies and arteriosclerotic stenoses or occlusions. This observation coincides with that of Zorgniotti et al. [20].

More valuable information on the hemodynamics in the penile vessels is provided by Doppler examination of the four arteries in the proximal and distal segment with quantification of the Doppler signal. The problem in the assessment of abnormal penile arterialization is to find a correlation between the number and the caliber of the penile arteries and the extent of the associated functional impairment.

Superficial doreal artery

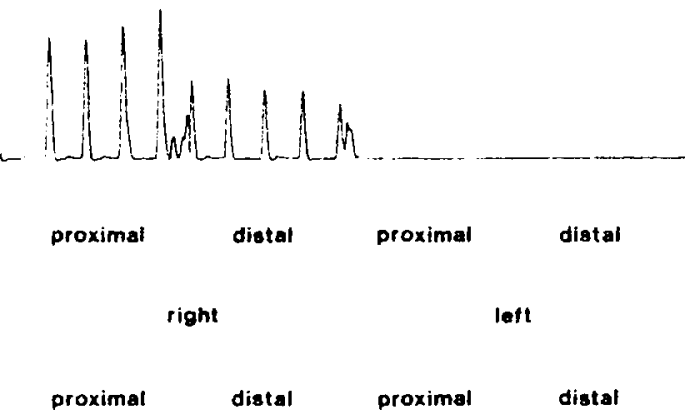

A

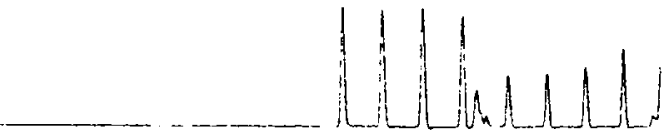

Deep cavernosal artery
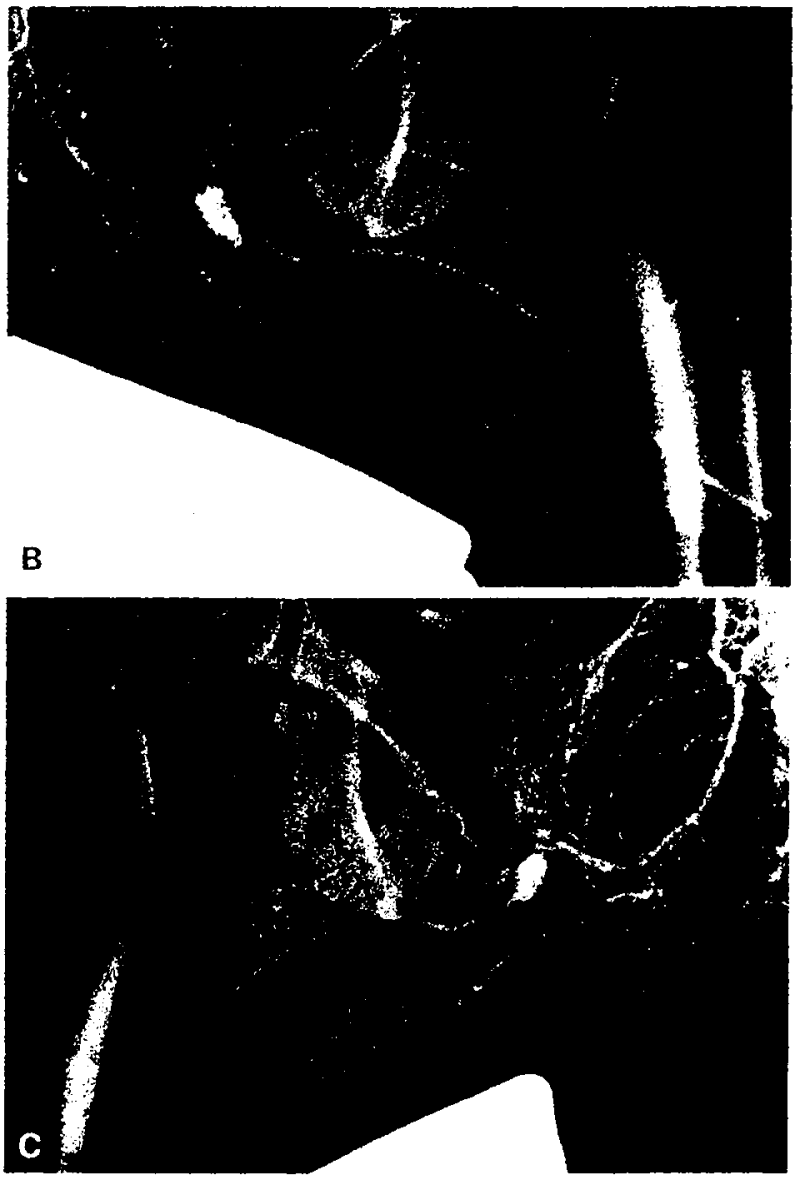

Fig. 4A. Doppler recording of the four penile arteries in a patient with bilateral vascular anomalies shows a strong Doppler signal trom the right superficial dorsal artery and from the left deep cavernosal artery, and a missing Doppler signal from the right deep cavernosal artery and from the left superficial dorsal artery. B. Selective arteriography of the right internal pudendal artery reveals only a superficial dorsal anery $(\rightarrow)$ and a missing deep cavernosal artery. C. Selective arteriography of the left internal pudendal artery reveals only a deep cavernosal $(\rightarrow)$ and a missing superficial dorsal artery. 


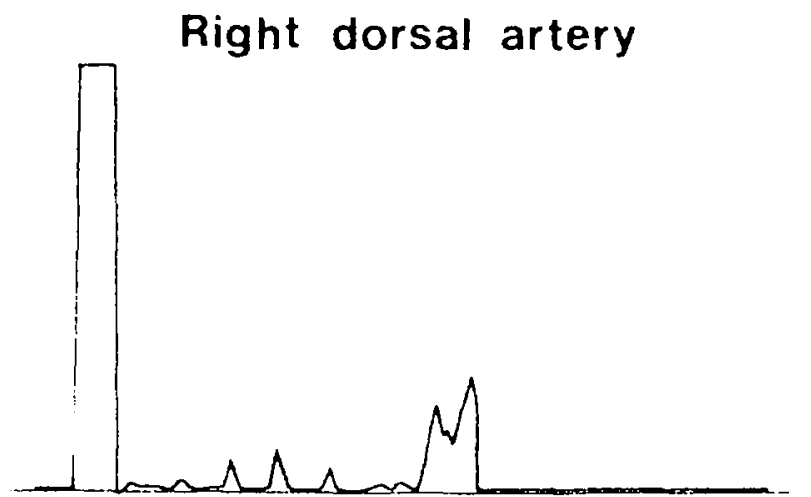

A proximal distal
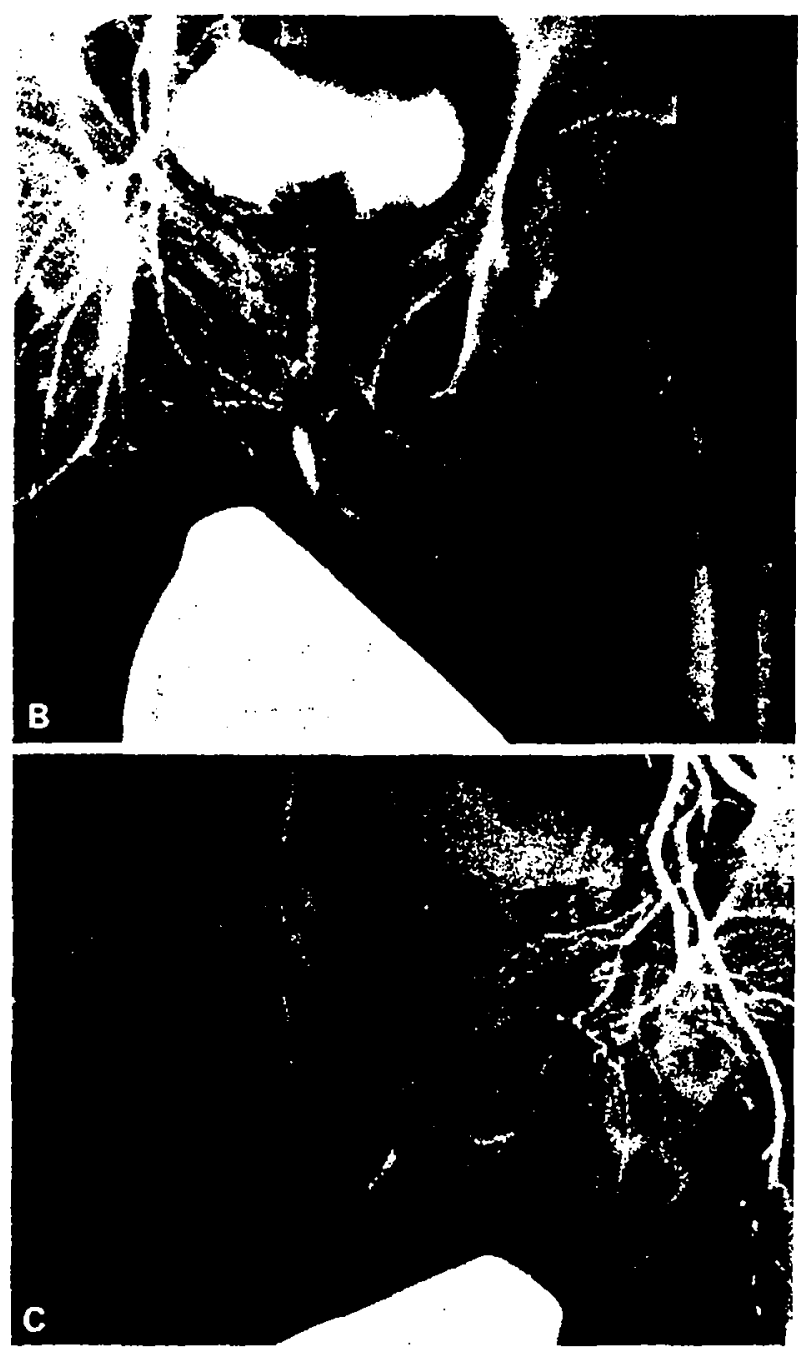

Fig. 5A. Doppler examination of the four penile arteries in a patient with severe arteriosclerosis revealed only a poor signal from the proximal right superticial dorsal artery. B. Selective arteriography of the right internal pudendal artery reveals stenoses in segment III $\rightarrow$, occlusion of the deep cavernosal artery, and a narrow superficial dorsal artery. C. Seleclive arteriography of the left side shows a long segmental stenosis of the internal pudendal artery $(\rightarrow)$, and occlusion of the deep cavernosal and superficial dorsal arteries.
Doppler ultrasound of 30 young potent men showed that hypoplasia or aplasia of one dorsal artery is common $(\sim 30 \%)$. and certainly does not lead to primary impotence [12]. In addition, arteriographic findings revealed that arterial anomalies must be severe, bilateral, and involving the deep cavernosal artery in order to cause primary erectile dysfunction [11]. With increasing age we believe that minor abnormalities of the deep caversonal arteries become more important as a cause of secondary impotence, especially when accompanied with risk factors of arteriosclerosis. This interpretation is in accord with results of our pharmacological test using the combination of $7.5 \mathrm{mg}$ papaverine and 0.25 mg phentolamine in 100 multidisciplinary evaluated patients [5]. To gain full erection, the patients with congenital abnormalities of the deep cavernosal arteries needed more than $0.5 \mathrm{ml}$ solution of the vasoactive drugs, whercas a control group of potent men reached full erection with this dose. Therefore. we consider these arterial abnormalities to be hemodynamically relevant arterial inflow disturbances. and a cause of secondary erectile dysfunction. (With regard to the relevance of arterial variants as cause of erectile dysfunction, also see Bähren et al., this issue.)

The comparative examinations with angiography showed a high accuracy $(95 \%)$ of Doppler in localization of penile arteries. Doppler ultrasound failed predominantly in the case of hypoplastic vessels, where the flow values were below the detection limit of Doppler ultrasound technique. The sensitivity of Doppler ultrasound in demonstrating a pathological arterial pattern was 93.8\%. Doppler examination of the penis was able to show the pathological changes in all cases of hypoplasia or aplasia of penile arteries (Fig. 4) and in most cases of arteriosclerotic occlusions and stenoses causing impaired penile circulation (Fig. 5). Our findings are similar to those of Jevtich and Maxwell [3, 21]. They observed agreement between Doppler and arteriography in the detection of obstructive vascular changes in about $90 \%$ of the cases and in the localization of the four penile arteries in $97 \%$.

Progress in the diagnosis of vascular impotence has been achieved by Doppler ultrasound of the penile arteries in association with IIVD. In comparative studies performing Doppler ultrasound in 15 patients with and without IIVD, the four penile arteries were more frequently detected after IIVD. The assessment of the Doppler sound showed an improvement at 16 sites and a deterioration at 3; the changes demonstrate to what extent the vasomotor reserve can be increased. The arterial inflow measured by means of IIVD is more reliable than that in the flaccid state because it reflects the hemodynamics in the functional state. Therefore, we currently 
perform Doppler ultrasound in the four penile arteries only after IIVD with $0.5 \mathrm{ml}$ of solution.

Doppler ultrasound of the penile vessels after intracavernosal injection of vasoactive drugs is a minimally invasive and accurate method to define the arterial inflow, and is therefore an important diagnostic step in the multidisciplinary evaluation program of erectile dysfunction $[3,4,6,12,19,22]$. The high diagnostic effectiveness of Doppler ultrasound reduces the need for invasive angiography of the internal pudendal artery. It is performed in primary as well as posttraumatic erectile dysfunction, and is an indispensable prerequisite for all intended revascularizations [23].

\section{References}

1. Casey WC (1980) "Penile blood pressure"-at clarification. Urology 15:47-48

2. Abelson D (1975) Diagnostic value of the penile pulse and blood pressure: A Doppler study of impotence in diabetics. $J$ Urol 113:636-639

3. Jevtich MJ (1984) Non-invasive vascular and neurologic tests in use for evaluation of angiogenic impotence. Inter Angio 3:225-232

4. Karacan J, Aslan C. Moore C. Aydin H, Sohmen T (1984) Penile blood-pressure index based on NPT monitoring of erectile capacity. Inter Angio 3:233-240.

5. Bähren W. Stief CG, Gall H. Scherb W, Gallwitz A, Altwein JE (1986) Rationelle Diagnostik der erektilen Dysfunktion unter Anwendung eines pharmakologischen Testes. Akt Lirol 17:177-180

6. Virag R, Frydman D, Legman M, Virag H (1984) Intracavernous injection of papaverine as a diagnostic and therapeutic method in erectile failure. Angiology 35:79-87

7. Zorgniotti AW, Lefleur RS (1985) Auto-injection of the corpus cavernosum with a vasoactive drug combination for vasculogenic impotence. J Urol 133:39-41

8. Lue TF, Hricak H, Marich KW, Tanagho EA (1985) Vasculogenic impotence evaluated by high-resolution ultrason- ography and pulsed Doppler spectrum analysis. Radiology 155:777-781

9. Ginestié J (1980) Pudendal angiography. In: Zorgniotti AW. Rossi G (eds) Vasculogenic impotence. Thomas, Springfield, Illinois pp 125-14?

10. Juhan CM, Huguet J, Clerissi P, Courjaret P (1980) Classification of internal pudendal artery lesions in one hundred cases. In: Zorgniotti AW, Rossi G (eds) Vasculogenic impotence. Thomas, Springfield, Illinois pp 153-163

11. Bähren W (1986) Erektile Dysfunktion: Selektive arteriographische Diagnostik und Therapie unter Anwendung vasoaktiver Substanzen. Habilitationsschrift, Ulm, pp 59-62

12. Gall H, Bähren W. Scherb W, Stief CG, Gallwitz A (1987) Diagnostik der vaskulïren Impotenz: Vergleich Dopplersonographie und Arteriographie. Hautarzt 18:716-722

13. Marshall M (1984) Praktische Doppler-Sonographie. Springer, Heidelberg, New York, Tokyo, pp 20-22

14. Jevtich MJ (1980) Importance of penile arterial pulse sound examination in impotence. $J$ Urol 124:820-824

15. Velcek D, Sniderman KW, Vaughan ED, Sos TA. Muecke EC (1980) Penile flow index utilizing a doppler pulse wave analysis to identify penile vascular insufficiency. J Urol 123:669-673

16. Kempczinski RF (1979) Role of the vascular diagnostic laboratory in the evaluation of male impotence. Am J Surg 138:278-282

17. Metz. P, Bengtsoon J (1981) Penile blood pressure. Scand J Urol Nephrol 15:161-164

18. Nath RL, Menzoian JO, Kaplan KH, McMillian TN, Siroky MB, Krane RJ (1981) The multidisciplinary approach to vasculogenic impotence. Surgery $89: 124-133$

19. Blaivas JG, O'Donnell TF. Gottlieb P, Labib KB (1980) Comprehensive laboratory evaluation of impotent men. $J$ Urol 124:201-204

20. Zorgniotti AW, Rossi G. Padula G, Makovsky RD (1980) Diagnosis and therapy of vasculogenic impotence. I Urol 123:674-677

21. Jevtich MJ, Maxwell DA (1983) Invasive vascular procedures. In: Krane RJ, Siroky MB, Goldstein I (eds) Male sexual dysfunction. Little, Brown and Company, Boston, Toronto. pp 165-175

22. van Arsdalen KN, Wein AJ (1983) A critical review of diagnostic tests used in the evaluation of the impotent male. World J Lrol 1:218-226

23. Bähren W, Lenz M, Porst H, Wierschin W (1984) Arteriographische Diagnostik der erektilen Impotenz. Fortschr Röntgenstr 140:447-452 